\title{
On the "General Acceptance"
}

\section{of Eyewitness Testimony Research}

\section{A New Survey of the Experts}

\author{
Saul M. Kassin \\ V. Anne Tubb and Harmon M. Hosch \\ Williams College \\ Amina Memon \\ University of Texas at El Paso \\ University of Aberdeen
}

In light of recent advances, this study updated a prior survey of eyewitness experts (S. M. Kassin, P. C. Ellsworth, \& V. L. Smith, 1989). Sixty-four psychologists were asked about their courtroom experiences and opinions on 30 eyewitness phenomena. By an agreement rate of at least $80 \%$, there was a strong consensus that the following phenomena are sufficiently reliable to present in court: the wording of questions, lineup instructions, confidence malleability, mug-shot-induced bias, postevent information, child witness suggestibility, attitudes and expectations, hypnotic suggestibility, alcoholic intoxication, the crossrace bias, weapon focus, the accuracy-confidence correlation, the forgetting curve, exposure time, presentation format, and unconscious transference. Results also indicate that these experts set high standards before agreeing to testify. Despite limitations, these results should help to shape expert testimony so that it more accurately represents opinions in the scientific community.

$\mathrm{n}$ recent years, and with increasing frequency, psychologists have served as expert witnesses in trials that contain possible erroneous eyewitness identifications. To assess the extent to which there is "general acceptance" of various eyewitness phenomena within the scientific community (a criterion for the admissibility of scientific evidence, initially enunciated in Frye $v$. United States, 1923), Kassin, Ellsworth, and Smith (1989) surveyed 63 eyewitness experts for their views on the reliability of 19 propositions. Their survey revealed that whereas certain research findings were judged to be reliable by most experts (e.g., the effects of exposure time, lineup instructions, the wording of questions, preevent expectations, postevent information, and the accuracy-confidence correlation), others did not elicit high levels of consensus (e.g., the effects of stress, event violence, gender, weapon focus, hypnotic retrieval techniques, and training in eyewitness observation).

By providing empirical evidence of the consensus within the community of experts, this survey has proved useful to judges ruling on the admissibility of expert witnesses; psychologists needing to determine the appropriate contents of their testimony; and cross-examiners seeking to discredit experts who overstate, understate, or in other ways misrepresent the literature. In light of the kinds of substantive disputes likely to erupt in the courtroom (Leippe, 1995; Penrod, Fulero, \& Cutler, 1995), the net effect, it was hoped, was to encourage expert testimony that more accurately reflects the consensus of opinions within the scientific community.

The time has come for Kassin et al.'s (1989) survey of experts to be updated. Since its publication, there has been a surge of new and important research developments in the area (for reviews, see Cutler \& Penrod, 1995; Ross, Read, \& Toglia, 1994; Sporer, Malpass, \& Koehnnken, 1996; Thompson et al., 1998; Wells, 1993). There has also been a surge of activity directed at the application of eyewitness research findings within the legal system. In 1996, the National Institute of Justice reported on 28 wrongful convictions, cases in which convicted felons were exonerated by DNA evidence after varying numbers of years in prison. Remarkably, all of these cases contained one or more false identifications (Connors, Lundregan, Miller, \& McEwen, 1996). More recently, the number of DNA exoneration cases had climbed to 62 (including 8 individuals who had been sentenced to death) -52 of which contained identifications from 77 confident but mistaken eyewitnesses (Scheck, Neufeld, \& Dwyer, 2000). In response to these newly documented miscarriages of justice, a group of eyewitness researchers - as part of an initiative of the American Psychology-Law Society (Division 41 of the American

Editor's note. David Faigman served as action editor for this article.

Author's note. Saul M. Kassin, Department of Psychology, Williams College; V. Anne Tubb and Harmon M. Hosch, Department of Psychology, University of Texas at El Paso; Amina Memon, Department of Psychology, University of Aberdeen, Aberdeen, Scotland.

We thank LavEarl Moore for help in compiling lists of experts and posting questionnaires and the University of Texas at El Paso Research Incentive Program for supporting this research.

Correspondence concerning this article should be addressed to Saul M. Kassin, Department of Psychology, Williams College, Bronfman Science Center, Williamstown, MA 01267 . Electronic mail may be sent to skassin@williams.edu. 
Psychological Association)-wrote a scientific review article that contained specific procedural rules for how to minimize errors made in the collection of eyewitness identifications (Wells et al., 1998). In 1999, the National Institute of Justice-at the request of former Attorney General Janet Reno-assembled a multidisciplinary working group of police, prosecutors, defense attorneys, and research psychologists, who published a "how to" manual, the first of its kind, entitled Eyewitness Evidence: A Guide for Law Enforcement (for a discussion of how these guidelines were developed, see Wells et al., 2000).

In addition to recent activity in the eyewitness arena, there have also been significant changes in the legal criteria by which judges admit or exclude expert testimony at trial. At the time the 1989 survey was conducted, most courts had relied heavily on the Frye test-that scientific testimony is admissible only if it is based on a theory or research finding that has "general acceptance in the particular field in which it belongs" (Frye v. United States, 1923, p. 1014). This criterion-which was specifically applied to eyewitness research in United States v. Amaral (1973)provided the motivational impetus for the original survey of experts.

Since that time, the evidentiary landscape has changed in significant ways. In Daubert v. Merrell Dow Pharmaceuticals, Inc. (1993), the U.S. Supreme Court urged trial judges to serve as more active gatekeepers by ascertaining whether an expert proffers testimony that is scientific and will assist the trier of fact. The Court thus shifted from the prior emphasis on general acceptance to the broader question of whether the testimony would be based on information that is not only relevant but reliable and valid-and obtained through sound scientific methods. ${ }^{1}$ The Court then extended this opinion in Kumho Tire Co., Ltd. v. Carmichael et al. (1999), in which it stated that Daubert's basic principles and the gatekeeping function assigned to trial judges may also be applied, albeit flexibly, to engineers and other nonscientific experts who proffer "technical" or "other specialized knowledge."

The Daubert ruling applies only to federal courts. Indeed, although many states followed suit, some did so only in part, and still others retained their existing standards - with 17 states continuing to use the Frye test (Berger, 2000; Faigman, Kaye, Saks, \& Sanders, 1997). In addition, as the majority opinion in Daubert makes clear, trial judges may still consider opinions within the community of experts in determining the admissibility of expert testimony ("general acceptance can yet have a bearing on the inquiry"; Daubert, 1993, p. 2797). Thus, as Leippe (1995) noted, Kassin et al.'s (1989) survey can have an important bearing on the extent to which different propositions about eyewitness testimony, on an item-by-item basis, are deemed reliable enough to be presented at trial. In Daubert, the U.S. Supreme Court majority asserted with confidence "that federal judges possess the capacity to undertake this review" (p. 2796). Lacking the training and experience necessary to evaluate psychological theories, research methods, error rates, and even the quality of peer-reviewed journals, judges would thus benefit greatly from the opinions of experts, whose collective wisdom presumably takes such considerations into account.

The present study was conducted with three goals in mind. First, we sought to update expert opinions on the classic eyewitness propositions tested in the original survey. In discussing the forensic usefulness of their results, Kassin et al. (1989) noted that as research accumulates, and as the effects of known factors are modified, expert opinion is likely to change. Their survey thus needs to be updated periodically to account for new research developments. To illustrate the point, Kassin et al. (1989) noted that when their data were collected, there was little direct evidence for the proposition that "the presence of a weapon impairs a witness's ability to accurately identify the perpetrator's face." No doubt aware of this issue, their experts split about 50-50 on the reliability of this statement. Yet, shortly thereafter, this weapon focus effect was demonstrated in several independent studies (see studies analyzed in Steblay, 1992).

Our second objective was to assess expert opinions on relatively new phenomena not previously tested. After the initial survey, for example, new studies were conducted on such topics as child witnesses (Ceci \& Bruck, 1995; Poole \& Lamb, 1998), repressed and/or false memories of trauma (Loftus, 1993; Pezdek \& Banks, 1996; Read \& Lindsay, 1997), the effects of alcohol (Yuille \& Tollestrup, 1990), the processes by which eyewitnesses make identifications (Dunning \& Stern, 1994; Sporer, 1993), sequential versus simultaneous presentations of photographic arrays and lineups (R. C. L. Lindsay, Lea, \& Fulford, 1991; Wells, 1993), the malleability of confidence and other retrospective reports of the eyewitnessing experience (Luus \& Wells, 1994; Shaw, 1996; Wells \& Bradfield, 1998, 1999), factors that moderate the correlation of accuracy and confidence (Kassin, Rigby, \& Castillo, 1991; D. S. Lindsay, Read, \& Sharma, 1999; Penrod \& Cutler, 1995; Robinson \& Johnson, 1999; Sporer, Penrod, Read, \& Cutler, 1995), and the commonsense assumptions about eyewitnesses held by laypersons and members of the legal profession (Devenport, Penrod, \& Cutler, 1997; Kassin \& Barndollar, 1992; Stinson, Devenport, Cutler, \& Kravitz, 1996, 1997).

Our third goal was to reestimate the level of expert witness activity occurring in today's criminal and civil courtrooms. To compare these data with those obtained in the 1989 survey, we posed the same set of questions. Thus, we asked respondents to indicate separately how often they had been asked to testify, had agreed to testify, and had actually testified at trial as an eyewitness expert for the plaintiff or the defense. In an open-ended question, we also asked respondents to indicate whether they had ever declined a request to testify and the reasons for that decision.

${ }^{1}$ In Daubert, the Supreme Court offered four questions as potentially helpful--though not necessary or definitive-to this inquiry: (a) whether the theories or methods used by the expert to formulate an opinion can be tested, (b) whether they have been subjected to peer review, (c) whether there is a measurable error rate, and (d) whether the theories or methods are generally accepted within the expert's community. 
In light of the criteria articulated in Daubert, we also asked respondents to indicate for each item whether their opinion was based on published, peer-reviewed, scientific research.

\section{Method}

\section{The Experts}

The following sources and resources were used to generate a list of experts: the membership rosters of Division 41 of the American Psychological Association, also known as the American Psychology-Law Society; the Society of Applied Research on Memory and Cognition; and the attendee lists of the 1995 and 1997 European Association of Psychology and Law biennial meetings. We identified members of these associations who had conducted eyewitness research. This list was then supplemented by a PsycINFO search for individuals who had published an article, book chapter, or other paper on eyewitness identifications during the previous 10 years. Finally, the names of eyewitness experts were solicited from subscribers to the PSYCHLAW listserve, an electronic communication network.

Questionnaires were mailed to a total of 197 prospective respondents. Of these respondents, 53\% were employed in the United States. The others were from the United Kingdom, Canada, Germany, Australia, the Netherlands, Spain, New Zealand, Israel, Italy, Sweden, Denmark, and France. Six individuals returned the questionnaire, saying they did not have time to complete it or no longer considered themselves to be experts. In 5 other instances, the envelopes were sent to the wrong name, to an incorrect address, or to individuals who had died. From the remaining population of 186 prospective participants, 64 returned data in usable form, yielding a $34 \%$ response rate. With regard to their areas of specialization, 34 respondents described their primary area as cognitive psychology, 17 as personality/social, 6 as child/developmental, and 3 as clinical/counseling. Four respondents identified themselves by combinations of two or more specific areas.

For confidentiality purposes, we did not require respondents to identify themselves on their questionnaires, so it was not possible to precisely assess the ways in which our sample resembled and differed from the population of 186 eligible participants. We do know that 62 of the 64 respondents had a Ph.D. in psychology (4 had also earned a J.D.; 1 had only a D.S., and another had only an M.A.) as did all but 3 members of the total population. We also compared the numbers of eyewitness publications selfreported by respondents with the actual publication numbers for the list of all prospective participants, as derived from PsycINFO, and we found that respondents constituted a highly prolific subgroup ( $M=17.98$ ) of the total population $(M=7.92), Z=3.66, p<.001$. It appears that the experts in our study could be described as a blue-ribbon group of leading researchers. The specific magnitude of the difference cannot be known, however, because the respondent data were based on self-reports-not on actual publication numbers.

\section{The Questionnaire}

Our questionnaire contained 30 statements concerning the accuracy of eyewitness testimony. Seventeen of the 21 items from the 1989 survey were retained. To minimize the length of our instrument, 2 of the original items (pertaining to sex differences and the tendency to overestimate event durations) were dropped, and the 2 items on cross-race identifications were combined into a single generally stated principle (in the original instrument, cross-race effects on Black and White witnesses were separately assessed). In light of the research literatures and controversies that developed in the 1990s, 13 new items were added. These items addressed simultaneous versus sequential lineups, prelineup exposure to mug shots, child witnesses, the diagnostic value of identification reaction times, the repression of traumatic experiences, and the recovery of repressed memories. The complete set of 30 statements is presented in Table 1.

Five questions accompanied each statement. First, respondents were asked to characterize the reliability of the proposition described. As in the original survey, there were seven response alternatives: (a) "the evidence suggests the reverse is probably true," (b) "the evidence does not support it," (c) "the evidence is inconclusive," (d) "the evidence tends to favor it," (e) "the evidence is generally reliable," (f) "the evidence is very reliable," or (g) "I don't know." Next, respondents were asked to indicate, yes or no, whether they thought the phenomenon "was reliable enough for psychologists to present it in courtroom testimony" The third question asked, yes or no, "Under the right circumstances, would you be willing to testify in court that this phenomenon is reliable?" Fourth, we asked respondents to reflect on whether their opinion on the issue was "based on published, peer reviewed, scientific research." Fifth, we asked respondents for their opinion on whether "most jurors believe this statement to be true as a matter of common sense."

Following the specific questions on the 30 eyewitness phenomena, respondents were asked several questions concerning their personal backgrounds and experiences. Specifically, we asked about their professional credentials (degrees obtained, primary areas of specialization, memberships in the American Psychological Association and the American Psychological Society), relevant scholarly achievements (number of eyewitness publications in scientific journals, law reviews, books, chapters, and magazines or newsletters), and courtroom experience (the estimated number of times they were asked to testify, the number of times they agreed to testify, and the number of times they actually testified). For this last set of questions, we asked respondents to specify how often they had been called on criminal or civil cases and whether it was by the prosecution (plaintiff) or the defense. In parallel with Kassin et al.'s (1989) survey, two more general questions were then asked: (a) "What do you see as the primary role of the eyewitness expert: to educate the jury, assist a particular party, or other (please specify)?" and (b) "In general, would 
Table 1

Eyewitness Topics and Statements

Topic Statement

1. Stress

2. Weapon focus

3. Showups

4. Lineup fairness

5. Lineup instructions

6. Exposure time

7. Forgetting curve

8. Accuracy-confidence

9. Postevent information

10. Color perception

11. Wording of questions

12. Unconscious transference

13. Trained observers

14. Hypnotic accuracy

15. Hypnotic suggestibility

16. Attitudes and expectations

17. Event violence

18. Cross-race bias

19. Confidence malleability

20. Alcoholic intoxication

21. Mugshot-induced bias

22. Long-term repression

23. False childhood memories

24. Discriminability

25. Child witness accuracy

26. Child suggestibility

27. Description-matched lineup

28. Presentation format

29. Elderly witnesses

30. Identification speed
Very high levels of stress impair the accuracy of eyewitness testimony.

The presence of a weapon impairs an eyewitness's ability to accurately identify the perpetrator's face.

The use of a one-person showup instead of a full lineup increases the risk of misidentification.

The more members of a lineup resemble the suspect, the higher is the likelihood that identification of the suspect is accurate.

Police instructions can affect an eyewitness's willingness to make an identification.

The less time an eyewitness has to observe an event, the less well he or she will remember it.

The rate of memory loss for an event is greatest right after the event and then levels off over time.

An eyewitness's confidence is not a good predictor of his or her identification accuracy.

Eyewitness testimony about an event often reflects not only what they actually saw but information they obtained later on.

Judgments of color made under monochromatic light (e.g., an orange streetlight) are highly unreliable.

An eyewitness's testimony about an event can be affected by how the questions put to that witness are worded.

Eyewitnesses sometimes identify as a culprit someone they have seen in another situation or context.

Police officers and other trained observers are no more accurate as eyewitnesses than is the average person.

Hypnosis increases the accuracy of an eyewitness's reported memory.

Hypnosis increases suggestibility to leading and misleading questions.

An eyewitness's perception and memory for an event may be affected by his or her altitudes and expectations.

Eyewitnesses have more difficulty remembering violent than nonviolent events.

Eyewitnesses are more accurate when identifying members of their own race than members of other races.

An eyewitness's confidence can be influenced by factors that are unrelated to identification accuracy.

Alcoholic intoxication impairs an eyewitness's later ability to recall persons and events.

Exposure to mug shots of a suspect increases the likelihood that the witness will later choose that suspect in a lineup.

Traumatic experiences can be repressed for many years and then recovered.

Memories people recover from their own childhood are often false or distorted in some way.

It is possible to reliably differentiate between true and false memories.

Young children are less accurate as witnesses than are adults.

Young children are more vulnerable than adults to interviewer suggestion, peer pressures, and other social influences.

The more that members of a lineup resemble a witness's description of the culprit, the more accurate an identification of the suspect is likely to be.

Witnesses are more likely to misidentify someone by making a relative judgment when presented with a simultaneous (as opposed to sequential) lineup.

Elderly eyewitnesses are less accurate than are younger adults.

The more quickly a witness makes an identification upon seeing the lineup, the more accurate he or she is likely to be.

Note. The first 18 items were retained from the original survey. In the present instrument, Item 14 was stated positively rather than negatively, and Item 18 combined initially separate items for Black and White witnesses. 
you say that juries are better equipped to evaluate eyewitness testimony with or without the aid of a competent expert (or is there no difference)?' Finally, we asked respondents to list any eyewitness topics about which they had testified that were not covered in the questionnaire and if they had ever declined to testify, to list the reasons for that decision.

\section{Results and Discussion}

\section{The Experts}

As we noted earlier, the experts in our sample were a prolific group with regard to research productivity. Ninetytwo percent had published one or more books, chapters, or articles on the psychology of eyewitness identification. On average, respondents had authored or edited 2.15 books, 6.54 chapters, 13.22 scientific journal articles, 1.42 law review articles, and 5.38 magazine or newsletter articles.

In addition to being active researchers and writers, many of our respondents were also actively involved in the judicial system. Seventy-eight percent had been asked to testify as eyewitness experts on at least one occasion-and an estimated average of 33.38 times. In those cases, they said they agreed to testify an estimated $78 \%$ of the time. And in cases in which they did agree, they actually testified an estimated $92 \%$ of the time. In an estimated $29 \%$ of these latter cases, our respondents were countered in court by an opposing expert.

Consistent with the results of the 1989 survey, the requests for expert testimony were not equally distributed across parties in criminal and civil proceedings. As presented in Table 2, our experts were asked to testify more often in criminal cases ( $n=3,150 ; 93 \%$ of all requests) than in civil cases ( $n=220 ; 7 \%$ of requests). By far, the lion's share of requests for expert assistance were from criminal defendants ( $n=3,016 ; 89 \%$ of all requests).

It is striking to compare the number of experts who agreed to testify with those who did so in the 1989 survey.
In absolute numbers, our respondents were called on to testify more frequently than in the past $(N s=3,369$ and 1,268 , respectively), but they were less likely to agree to do so (the agreement rates were $74 \%$ in 1989 and $41 \%$ in the present survey, $Z=16.89, p<.001$ ). When they did agree to testify, a significantly greater percentage actually did so than was the case in the previous survey $(70 \%$ and $51 \%$, respectively), $Z=6.97, p<.001$.

Consistent with the earlier finding that eyewitness experts agreed to become involved more often in civil than criminal cases (the 1989 agreement rates were $91 \%$ and $71 \%$, respectively), we found that the agreement rate was higher $(76 \%)$ when experts were sought by civil plaintiffs than by civil defendants, criminal prosecutors, and criminal defendants $(43 \%, 48 \%$, and $40 \%$, respectively; $p s<.001)$. In contradiction to the charge that eyewitness experts are liberally biased toward criminal defendants, it is important to note that respondents were just as likely to agree to assist the prosecution as they were the defense in criminal cases, $Z=0.47, n s$.

There are two possible explanations for the finding that experts are less agreeable today than in the recent past. One is that today's experts testify as often in absolute terms but that they agree proportionally fewer times because they receive so many more requests - about three times more per expert. A second possibility is rooted in the fact that our experts were more active and productive researchers than those in Kassin et al.'s (1989) sample, and so perhaps they had less time or inclination to become involved as consultants in actual cases. Of the 49 experts who had been asked to testify at some time, all of them reported that they had declined a request for expert testimony on at least one occasion. There were various reasons for this decision. Nineteen respondents cited moral or ethical concerns (e.g., "I could not say what the attorney wanted me to say") and the personal belief that the defendant was guilty of the crime charged. Ten said they had declined to testify be-

Table 2

Estimated Number of Times Respondents Were Asked to Testify, Agreed to Testify, Actually Testified, and Were Opposed in Court

\begin{tabular}{|c|c|c|c|c|c|c|c|c|c|c|}
\hline \multirow[b]{3}{*}{ Action } & \multicolumn{4}{|c|}{ Criminal } & \multicolumn{4}{|c|}{ Civil } & & \\
\hline & \multicolumn{2}{|c|}{ Prosecution } & \multicolumn{2}{|c|}{ Defense } & \multicolumn{2}{|c|}{ Plaintiff } & \multicolumn{2}{|c|}{ Defense } & \multicolumn{2}{|c|}{ Total } \\
\hline & $n$ & $\%$ & $n$ & $\%$ & $n$ & $\%$ & $n$ & $\%$ & $n$ & $\%$ \\
\hline Asked to testify & 134 & & 3,016 & & 62 & & 158 & & 3,370 & \\
\hline Agreed to testify & 65 & $48^{a}$ & 1,193 & $40^{\circ}$ & 47 & $76^{\circ}$ & 68 & $43^{\circ}$ & 1,373 & $41^{\mathrm{a}}$ \\
\hline Actually testified & 56 & $86^{b}$ & 837 & $70^{b}$ & 27 & $57^{b}$ & 40 & $44^{b}$ & 960 & $70^{\mathrm{b}}$ \\
\hline $\begin{array}{l}\text { Opposed } \\
\text { Total yield }\end{array}$ & 25 & $\begin{array}{l}45^{c} \\
42^{d}\end{array}$ & 30 & $24^{\mathrm{c}}$ & 9 & $\begin{array}{l}33^{c} \\
44^{d}\end{array}$ & 12 & $\begin{array}{l}30^{c} \\
25^{d}\end{array}$ & 76 & $\begin{array}{r}8^{\mathrm{c}} \\
28^{\mathrm{d}}\end{array}$ \\
\hline
\end{tabular}

a Agreement rate (i.e., percentage of times experts agreed to testify when asked). b Percentage of experts who after agreeing to testify actually did so. "Percentage of experts whose testimony was opposed in court. dercentage of experts initially asked who ultimately testified. 
cause they were busy or were pressed for time. Eight declined because they did not feel competent to address the specific phenomenon pertinent to the case (many of these requests were for testimony on the effects of hypnosis on the recovery of repressed memories). Other reasons for not testifying were that the phenomenon in question was not important relative to other evidence (e.g., the defendant's fingerprints) or was not sufficiently reliable or that the respondent did not think that expert testimony would assist the trier of fact.

To examine individual differences in generalized assessments of eyewitness phenomena, we next compared respondents who were (a) high versus low in research productivity and (b) high versus low in courtroom experience (both categorizations were derived by median split). For each respondent, we summed across the 30 eyewitness items the number of affirmative responses they gave to the critical question, "Do you think that this phenomenon is reliable enough for psychologists to present in courtroom testimony?" A two-way analysis of variance (Research Productivity $\times$ Courtroom Experience) on these 0-30 scores revealed a nonsignificant tendency for respondents with a high number of publications to judge more phenomena as "reliable enough" compared with those with a lower number of publications, $F(1,54)=3.03, p<.10(M \mathrm{~s}=$ 20.86 and 18.28 , respectively). There was no significant difference on this measure as a function of courtroom experience, $F(1,54)<1(M \mathrm{~s}=20.03$ and 18.96 for high- and low-frequency experts, respectively), nor was there a significant interaction between the two factors, $F(1,54)<1$.

A similar two-way analysis of variance was conducted on the critical question, "Would you be willing to testify that this phenomenon is reliable?" Again, for each respondent, we summed across all items the number of affirmative responses, yielding scores that ranged from 0 to 30 . On this measure, a significant and interesting main effect for research productivity indicated that high-publication respondents were willing to testify about more items than were low-publication respondents $(M \mathrm{~s}=18.08$ and 12.99 , respectively), $F(1,54)=4.87, p<.05$. There were no significant effects for courtroom experience, $F(1,54)=$ $1.45, p<.25$, and no interaction, $F(1,54)<1$.

\section{Judgments of Eyewitness Phenomena}

For each of the 30 eyewitness propositions, we sought to assess (a) how the experts as a group characterized the reliability of the phenomenon; (b) whether they saw the phenomenon as sufficiently reliable to present in court; (c) whether they would personally be willing to testify about it; (d) whether they saw their opinion on reliability as being based on published, peer-reviewed, scientific research; and (e) whether they thought that jurors were aware of the phenomenon as a matter of common sense. Table 3 presents the complete distribution of responses on the reliability question for each of the propositions. More important from a practical standpoint, Table 4 shows for each item the percentage of experts who answered "yes" to the "re- liable enough," "would you testify," "research basis," and "juror commonsense" questions.

Comparisons with 1989 survey. For the 17 propositions that were retested, we compared the reliability assessments of our respondents with those initially provided by Kassin et al.'s (1989) experts. The most striking aspect of these comparisons was the degree of consistency in the two samples. As shown in Table 5, there were no significant shifts in most of the original items, and for some, the numbers were virtually identical. Thus, as before, most experts saw as sufficiently reliable expert testimony on the wording of questions ( $98 \%$ ), lineup instructions (98\%), attitudes and expectations (92\%), the accuracyconfidence correlation $(87 \%)$, the forgetting curve $(83 \%)$, exposure time $(81 \%)$, and unconscious transference $(81 \%)$. Also as before, there was less, if any, consensus on the effects of color perception in monochromatic light $(63 \%)$, observer training $(61 \%)$, high levels of stress $(60 \%)$, the accuracy of hypnotically refreshed testimony (45\%), and event violence (37\%).

Our experts saw two phenomena as significantly more reliable than did those who took part in the initial survey. These increases were obtained for the weapon focus effect $(87 \%$ and $57 \%), \chi^{2}(1, N=112)=13.61, p<.001$, and hypnotic suggestibility effects $(91 \%$ and $69 \%), \chi^{2}(1, N=$ $118)=9.67, p<.005$. The increased levels of acceptance for these latter propositions make sense in light of the substantial bodies of research in these areas over the ensuing decade. For example, Steblay (1992) conducted a metaanalytic review of the weapon focus effect and concluded that it is reliable across a wide range of settings-a conclusion that has been further corroborated in more recent studies (e.g., Pickel, 1999). In a similar manner, a great deal of recent theory and research has shed light on hypnosis in general (Kirsch \& Lynn, 1995) and on the risk of suggestibility effects on reported memories (Malinoski \& Lynn, 1999; McConkey \& Sheehan, 1995). Thus, as noted elsewhere with regard to the first survey (Kassin, Ellsworth, \& Smith, 1994), it appears that our experts were highly responsive to changes-and nonchanges-in the status of the scientific literature.

Proposifions nof previously tested. One of the main purposes of the present study was to assess expert opinion on important and recent eyewitness phenomena that were not previously tested. As described in Table 1, we tested 13 new propositions (Items 18-30). Table 4 shows that, in this subset of items, 6 were viewed by at least $80 \%$ of experts as reliable enough to be presented in court: that eyewitness confidence is malleable and influenced by factors unrelated to accuracy (95\%), that exposure to mug shots of a suspect increases the likelihood of his or her selection from a subsequent lineup (95\%), that young children are more vulnerable than adults to suggestion and other social influences (94\%), that alcohol impairs eyewitness performance $(90 \%)$, that eyewitnesses find it relatively difficult to identify members of a race other than their own $(90 \%)$, and that the risk of false identification is increased by the use of a simultaneous as opposed to sequential 
Table 3

Distribution of Reliability Judgments for the 30 Propositions

\begin{tabular}{|c|c|c|c|c|c|c|c|}
\hline Topic & 1 & 2 & 3 & 4 & 5 & 6 & 7 \\
\hline 1. Stress & 2 & 2 & 13 & 17 & 19 & 4 & 5 \\
\hline 2. Weapon focus & 0 & 0 & 3 & 14 & 27 & 15 & 4 \\
\hline 3. Showups & 3 & 3 & 6 & 10 & 16 & 15 & 10 \\
\hline 4. Lineup fairness & 5 & 5 & 4 & 7 & 15 & 11 & 14 \\
\hline 5. Lineup instructions & 0 & 0 & 0 & 3 & 17 & 36 & 5 \\
\hline 6. Exposure time & 0 & 1 & 7 & 11 & 14 & 25 & 2 \\
\hline 7. Forgetting curve & 1 & 4 & 5 & 7 & 18 & 24 & 3 \\
\hline 8. Accuracy-confidence & 1 & 1 & 3 & 15 & 16 & 24 & 1 \\
\hline 9. Postevent information & 1 & 0 & 2 & 2 & 16 & 42 & 0 \\
\hline 10. Color perception & 0 & 0 & $\overline{1}$ & 2 & 7 & 10 & 43 \\
\hline 11. Wording of questions & 0 & 0 & 0 & $\overline{1}$ & 14 & 48 & 0 \\
\hline 12. Unconscious transference & 0 & 1 & 3 & 20 & 16 & 22 & 1 \\
\hline 13. Trained observers & 1 & 1 & 29 & 13 & 2 & 1 & 17 \\
\hline 14. Hypnotic suggestibility & 1 & 0 & 4 & 5 & 22 & 26 & 5 \\
\hline 15. Attitudes and expectations & 0 & 0 & 0 & 10 & 26 & 27 & 0 \\
\hline 16. Event violence & 8 & 7 & 17 & 11 & 5 & 1 & 14 \\
\hline 17. Confidence malleability & 0 & 0 & 0 & 5 & 18 & 37 & 2 \\
\hline 18. Cross-race bias & 0 & 0 & 1 & 16 & 19 & 25 & 2 \\
\hline 19. Hypnotic accuracy & 28 & 28 & 5 & 0 & 0 & 0 & 2 \\
\hline 20. Alcoholic intoxication & 0 & 1 & 1 & 13 & 20 & 19 & 9 \\
\hline 21. Mug-shot-induced bias & 0 & 0 & 0 & 12 & 31 & 19 & 1 \\
\hline 22. Long-term repression & 3 & 21 & 28 & 7 & 3 & 0 & 0 \\
\hline 23. False childhood memories & 0 & 2 & 7 & 22 & 14 & 16 & 3 \\
\hline 24. Discriminability & 14 & 25 & 15 & 4 & 1 & 2 & 3 \\
\hline 25. Child accuracy & 2 & 11 & 10 & 12 & 17 & 11 & 1 \\
\hline 26. Child suggestibility & 0 & 0 & 2 & 11 & 22 & 27 & 2 \\
\hline 27. Description-matched lineup & 3 & 3 & 4 & 8 & 15 & 10 & 19 \\
\hline 28. Presentation format & 1 & 0 & 2 & 6 & 20 & 20 & 13 \\
\hline 29. Elderly witnesses & 0 & 6 & 8 & 17 & 11 & 4 & 17 \\
\hline 30. Identification speed & 0 & 2 & 7 & 19 & 11 & 2 & 22 \\
\hline
\end{tabular}

Note. Evaluations of the research evidence were coded as follows: 1 = the reverse is probably true, $2=$ no support, $3=$ inconclusive, $4=$ tends to favor, $5=$ generally reliable, $6=$ very reliable, and $7=1$ don't know.

presentation format $(81 \%)$. Three additional propositions were endorsed by at least two thirds of our experts, these being that identification accuracy is increased by having foils that match the witness's description of the culprit $(71 \%)$, that young children are less accurate witnesses than adults $(70 \%)$, and that the memories people recover from childhood are often false or distorted in some way $(68 \%)$.

Finally, 4 of the new items were patently not endorsed by a majority of experts. On the notion that elderly witnesses are less accurate than younger adults, opinion was split on the "reliable enough" question $(50 \%)$. Eliciting consensus in a negative direction-that the research evidence was not reliable enough to be presented in courtmost of our experts did not endorse the propositions that identification speed is predictive of accuracy $(40 \%)$, that it is possible to differentiate between true and false memories $(32 \%)$, or that traumatic experiences can be repressed for many years and then recovered ( $22 \%)$. It is quite clear that respondents made distinctions among the phenomena we had assessed, seeing some but not others as reliable enough for presentation to a judge and a jury.

\section{How Reliable Is "Reliable Enough"?}

Over the years, psychologists with opposing views on the role of eyewitness experts in court have debated the question of how clear and convincing a body of research must be before it is worthy enough to be offered in court. To address this issue, we compared each respondent's assessment of each proposition with his or her judgment of whether that proposition was reliable enough for testimony. Table 6 reports percentages of experts who judged each topic to be reliable enough and who would themselves testify about it. Data across respondents and items were combined to identify the percentages of experts who believed that psychologists should testify-and that they would testify-at varying levels of reliability.

This analysis revealed that experts were internally consistent in their assessments. Only $4 \%$ were willing to 
Table 4

Discrete Judgments and Opinions Concerning the 30 Eyewitness Topics Tested

\begin{tabular}{|c|c|c|c|c|}
\hline Topic & $\begin{array}{c}\text { Is it } \\
\text { reliable? }\end{array}$ & $\begin{array}{c}\text { Would you } \\
\text { testify? }\end{array}$ & $\begin{array}{l}\text { Research } \\
\text { basis? }\end{array}$ & $\begin{array}{c}\text { Common } \\
\text { sense? }\end{array}$ \\
\hline Wording of questions & 98 & 84 & 97 & 25 \\
\hline Lineup instructions & 98 & 79 & 95 & 39 \\
\hline Confidence malleability & 95 & 79 & 95 & 10 \\
\hline Mug-shot-induced bias & 95 & 77 & 97 & 13 \\
\hline Postevent information & 94 & 83 & 98 & 17 \\
\hline Child suggestibility & 94 & 81 & 100 & 73 \\
\hline Attitudes and expectations & 92 & 70 & 94 & 31 \\
\hline Hypnotic suggestibility & 91 & 76 & 90 & 19 \\
\hline Alcoholic intoxication & 90 & 61 & 76 & 95 \\
\hline Cross-race bias & 90 & 72 & 97 & 65 \\
\hline Weapon focus & 87 & 77 & 97 & 34 \\
\hline Accuracy-confidence & 87 & 73 & 97 & 5 \\
\hline Forgetting curve & 83 & 73 & 93 & 29 \\
\hline Exposure time & 81 & 68 & 93 & 97 \\
\hline Presentation format & 81 & 64 & 93 & 0 \\
\hline Unconscious transference & 81 & 66 & 92 & 19 \\
\hline Showups & 74 & 59 & 85 & 30 \\
\hline Description-matched foils & 71 & 48 & 82 & 30 \\
\hline Child accuracy & 70 & 59 & 91 & 78 \\
\hline Lineup fairness & 70 & 54 & 78 & 48 \\
\hline False childhood memories & 68 & 52 & 87 & 25 \\
\hline Color perception & 63 & 27 & 37 & 41 \\
\hline Stress & 60 & 50 & 98 & 37 \\
\hline Older witnesses & 50 & 38 & 77 & 66 \\
\hline Hypnotic accuracy & 45 & 34 & 89 & 55 \\
\hline Identification speed & 40 & 29 & 75 & 61 \\
\hline Trained observers & 39 & 31 & 76 & 73 \\
\hline Event violence & 37 & 29 & 79 & 14 \\
\hline Discriminability & 32 & 25 & 89 & 52 \\
\hline Long-term repression & 22 & 20 & 87 & 79 \\
\hline
\end{tabular}

Note. Numbers represent the percentage of experts who responded "yes" to each question. Topics are rank ordered according to their scores on the key question, "Do you think this phenomenon is reliable enough for psychologists to present in courtroom testimony?"

testify when they felt that a body of research was "inconclusive." When they believed there was "no support" for a proposition, $27 \%$ said they were willing to testify, presumably to say just that. Respondents were split when, as they saw it, the evidence "tends to favor" the issue or when it "suggests the reverse is probably true" (45\% and $44 \%$, respectively). Yet the vast majority of experts were willing to testify when they perceived the research evidence to be "generally reliable" (77\%) or, better yet, "very reliable" $(91 \%)$

\section{Role of Eyewitness Experts}

Central to debates on the nature, scope, and role of expert scientific testimony is the question of whether experts should serve as advocates for a party in the dispute or adopt a more neutral posture in an effort to educate the jury, as one might expect of a court-appointed expert. Thus, we asked whether the primary role of an eyewitness expert is to assist a particular party, educate the jury, or serve some other function. Among our 64 respondents, 49 (77\%) said that their primary purpose was to educate the jury, compared with only $3(5 \%)$ who sought to assist a particular party, and $4(6 \%)$ who cited a combination of purposes. An additional $8(13 \%)$ respondents cited other reasons, most notably: to educate trial judges, to train police officers on how to increase identification accuracy while minimizing error, and to influence legal policy on how eyewitness identification evidence should be collected.

A principle criterion for the admission of expert testimony is that it assist the trier of fact. Accordingly, Kassin et al. (1989) proposed a Bayesian-like test: that expert testimony be admitted to the extent that it offers to revise what jurors already believe as a matter of common sense (i.e., by informing them of research findings not intuitively known or correcting misconceptions not supported by research). As one can see in Table 4, respondents made sharp 
Table 5

Comparison of Reliability Judgments, 1989 and Present

\begin{tabular}{lcc}
\hline & \multicolumn{2}{c}{ Reliable enough to restify? } \\
\cline { 2 - 3 } Topic & 1989 & Present \\
\hline Stress & 71 & 60 \\
Weapon focus & 57 & $87^{\star}$ \\
Showups & 83 & 74 \\
Lineup fairness & 77 & 70 \\
Lineup instructions & 95 & 98 \\
Exposure time & 85 & 81 \\
Forgetting curve & 83 & 83 \\
Accuracy-confidence & 87 & 87 \\
Postevent information & 87 & 94 \\
Color perception & 66 & 63 \\
Wording of questions & 97 & 98 \\
Unconscious transference & 85 & 81 \\
Trained observers & 59 & $61^{\text {a }}$ \\
Hypnotic suggestibility & 69 & $91^{*}$ \\
Attitudes and expectations & 87 & 92 \\
Event violence & 36 & 37 \\
\hline a This item was reverse coded to make the present data comparable with those \\
of 1989.
\end{tabular}

distinctions among items along this dimension. For example, some phenomena were seen as falling well within the realm of common sense and as known by the average person (e.g., exposure time), whereas others were seen as highly nonintuitive (e.g., the low accuracy-confidence correlation). In a single question, we asked respondents to speculate as to whether juries were generally better equipped to evaluate eyewitnesses with or without the aid of a competent expert (a no-difference alternative was included). As in the 1989 survey, the result on this item was clear: Sixty-one respondents believed that eyewitness experts generally have a positive impact on juries $(95 \%)$, and 3 said there was no impact $(5 \%)$. Not a single respondent thought that juries were adversely affected.

\section{New Developments and Future Issues}

To explore new areas in the eyewitness landscape not specifically covered in our survey, respondents were asked if they had ever testified on issues other than those tested. In response to this question, several new areas were mentioned. The most frequently cited issue concerned voice recognition and the extent to which "earwitnesses" can identify people from the sound of their voice (Yarmey, Yarmey, \& Yarmey, 1994). Other issues cited concerned the effects on identification accuracy of disguise, retention interval, multiple exposures to a given suspect, cowitnesses, duration estimates, object recognition abilities, distinctive perpetrator characteristics, and use of the cognitive interview with child witnesses.

\section{General Discussion}

It has been more than 10 years since the publication of Kassin et al.'s (1989) original survey of eyewitness experts. Since that time, the field has expanded, with more researchers publishing more articles on more performance-relevant variables than in the past (most notably, this literature includes such explosive "new" topics as repressed and recovered memories and suggestibility effects in children). Since that time, parts of the American legal systemfollowing the U.S. Supreme Court's opinions in Daubert $v$. Merrell Dow Pharmaceuticals, Inc. (1993) and Kumho Tire Co., Ltd. v. Carmichael et al. (1999)-have altered the criteria that they use to admit scientific expert testimony. Since that time, researchers have identified dozens of settled cases in which innocent people convicted of capital and noncapital crimes have been exonerated by DNA testing (Connors et al., 1996; Scheck et al., 2000). Also since that time, the U.S. Department of Justice - with primary input from research psychologists-published guidelines for law enforcement on how to minimize error in the collection and preservation of eyewitness identification evidence (Technical Working Group for Eyewitness Evidence, 1999; see Wells et al., 2000). In short, the eyewitness landscape has changed a great deal in recent years, making it necessary to update judges, lawyers, and psychologists on the consensus that exists within the scientific community.

The present study revealed some important consistencies and some changes in the opinions of eyewitness experts. Like those sampled in 1989, our respondents judged many eyewitness phenomena as reliable enough for presentation in court. As indicated by an agreement rate of at least $80 \%$, there was a strong consensus, in descending order, on the reliability of the following 10 originally tested propositions: the wording of questions, lineup instructions, postevent information biases, attitudes and expectations,

\section{Table 6}

Percentages of Experts Who for Each Assessment of Reliability Judged the Topics to Be Reliable Enough and Would Themselves Testify

\begin{tabular}{lcc}
\hline & \multicolumn{2}{c}{ Judgment } \\
\cline { 2 - 3 } Opinion on reliability & $\begin{array}{r}\text { Reliable } \\
\text { enough? }\end{array}$ & $\begin{array}{c}\text { Would you } \\
\text { testify? }\end{array}$ \\
\hline Reverse is probably true & $56_{\mathrm{a}}$ & $44_{\mathrm{a}}$ \\
No support & $33_{\mathrm{b}}$ & $27_{\mathrm{b}}$ \\
Inconclusive & $77_{\mathrm{c}}$ & $4 \mathrm{c}$ \\
Tends to favor & $66_{\mathrm{a}}$ & $45_{\mathrm{a}}$ \\
Generally reliable & $97_{\mathrm{d}}$ & $77_{\mathrm{d}}$ \\
Very reliable & $100_{\mathrm{e}}$ & $91_{\mathrm{e}}$ \\
\hline
\end{tabular}

Note. Within each column, percentages without a common subscript differ at $p<.05$. 
hypnotic suggestibility, the accuracy-confidence correlation, weapon focus, the forgetting curve, exposure time, and unconscious transference (by a two-thirds margin, respondents also endorsed the item on showups). Aware of advances in the literature, our respondents, as a group, viewed two propositions more favorably than in the 1989 survey-those pertaining to hypnotic suggestibility and weapon focus. As before, however, they clearly did not endorse the items pertaining to stress, event violence, hypnotic accuracy, observer training, and color perception under monochromatic light (this last item elicited many "I don't know" responses). In short, our respondents were discriminating in their judgments and responsive to changes over time in the research evidence.

We also examined 13 eyewitness propositions that were not previously tested but that had drawn a great deal of recent attention. Being the first expert opinion data collected on these issues, the results were highly informative. Overall, six items were judged reliable by at least $80 \%$ of respondents. In order of their endorsement rates, these pertained to the malleability of confidence, exposure to mug shots, suggestibility of young children, alcoholic intoxication, the cross-race bias, and simultaneous versus sequential presentation format. By a lesser two-thirds consensus, respondents also judged as reliable the propositions that lineup foils should match the witness's description of the culprit, that young children are less accurate than adults, and that recovered childhood memories are often false. Again indicating that experts were discriminating in their opinions, most agreed that long-term repression and recovery and the related proposition that it is possible to differentiate true and false memories are not reliable enough for presentation in court. This result represents the first poll of eyewitness experts on this controversial topic (in this regard, it would be important to sample clinical psychologists whose perspectives do not emanate from the eyewitness area). In contrast to the consensus obtained on these various propositions, there was very little agreement (i.e., opinions were relatively split) on the new items pertaining to older witnesses and the correlation between identification speed and accuracy.

In terms of how eyewitness experts perceive and manage their activity in the courtroom, three sets of results indicate that they set relatively high standards for their own involvement. First, by examining the association between each respondent's perceptions of reliability and his or her willingness to testify, we found that most said they would agree to testify only on propositions they considered "generally reliable" and "very reliable." Second, across all propositions, respondents were far more likely to see a phenomenon as reliable enough for testimony (overall $M=$ 19.60) than to indicate a personal willingness to testify (overall $M=15.54$ ). Third, respondents were discriminating in their decisions to serve as expert witnesses. In comparison with the 1989 results, they were called on to testify more often, but they were less likely to agree to do so (the agreement rates were $74 \%$ in 1989 and $41 \%$ in the present sample). Of 49 respondents who had been asked to testify, every single one had declined the opportunity on at least one occasion-most often for moral or ethical reasons, a lack of time, or a perceived incompetence on the relevant issues.

There are two potential limitations of the present survey. One is that additional research published in years to come will inevitably force experts to revise at least some of their current assessments. Comparisons between the 1989 survey and our own offer the case in point. In the initial survey, for example, only $57 \%$ saw the weapon focus effect as reliable enough for expert testimony. Yet in light of the publication of later studies and a meta-analysis, $87 \%$ of our respondents judged this proposition in the affirmative. In a related vein, new research developments will make it necessary to add topics to be surveyed. Kassin et al. (1989) solicited opinions on 19 basic propositions. Our questionnaire contained 30 items, including 13 that were new. At a later time, it will similarly become necessary to further expand the scope of this inquiry.

It could be argued that the sampling of experts in this survey constitutes a second limitation. To identify our population of respondents, we sought individuals active in the eyewitness area, which raises an issue that has long plagued the Frye test, namely, that individuals with the most expertise in an area may also have the greatest motivation to present it in a favorable light. Thus, in Kumho Tire Co., Ltd. v. Carmichael et al. (1999), the Supreme Court anticipated that a trial judge might at times exclude proffered expert testimony because the discipline lacks the potential for reliability-despite a consensus within the community of experts (the only disciplines the Court singled out as examples were astrology and necromancy). This possible confounding of expertise and motivation implies that perhaps our respondents should have been drawn from a broader population of basic experimental psychologists who study noneyewitness processes or do not testify in court.

Such an approach may seem reasonable on its face, but it would create a different and serious problem, namely, that a broader sample of experimental psychologists would lack a necessary degree of familiarity with parts of the literature. Over the past quarter century, eyewitness research has become a specialized and highly technical area of application built on the shoulders of the mock witness paradigm and a focus on correctable "system variables" (Wells, 1993). As a result, there are many essential nutsand-bolts concepts (e.g., simultaneous and sequential presentation formats, valid vs. blank lineups, biased vs. unbiased instructions, and description-matched vs. suspectmatched foils) that are simply not known to the generalists among us.

Is there any evidence to suggest that our eyewitness experts comprised a Frye sample tainted by self-motivated interest? We do not think so. Indeed, close inspection of the data offers four bases of reassurance. The first and simplest is that $28(44 \%)$ of our respondents had never testified in court and so were not motivated in this regard (many were asked and declined the opportunity). Second, there is no 
support for a stereotype that some might hold-that a caricature-like distinction exists between pure scientists and forensic consultants. Thus, when we correlated the total number of publications per respondent with his or her courtroom experience, we found that very few fit the pure "scientist" or "consultant" profile. To the contrary, numbers of publications were positively-not negatively-associated with the number of times experts were asked to testify, $r(56)=.38, p<.002$; had agreed to testify, $r(56)=$ $.48, p<.001$; and had actually testified, $r(56)=.53, p<$ .001 . Third, as we reported earlier, we conducted an internal analysis to test the motivated self-interest hypothesis that experts who frequently testify in court, compared with those who do not, would endorse more of the 30 items surveyed as "reliable enough for psychologists to present in courtroom testimony." In fact, there was no significant difference-a result that was corroborated by the more specific comparison of the 35 respondents who had testified at least once with the 28 who had never testified ( $M \mathrm{~s}=$ 19.21 and 19.83, respectively). Fourth, although individual respondents disagreed in their assessments of certain principles, and although some were generally more demanding than others, the group as a whole was by no means uniformly accepting of all principles. Respondents discriminated quite reasonably among statements for which there was a wealth of experimental support and those for which there was not. And on an item concerning perceptions of color under monochromatic light, $67 \%$ of respondentsvery few of whom were trained in vision-candidly admitted, "I don't know."

The present results should provide needed guidance to judges (in their decision making at suppression hearings, trials, Daubert hearings, and on appeal), lawyers (in their examination of eyewitnesses and police who collect identification evidence), and psychological experts (who must determine which phenomena are reliable enough to present in court). The information contained herein should thus help to sharpen the direct and cross-examinations of eyewitness experts and shape the content of their testimony so that it more accurately reflects opinions within the scientific community. From a paradigmatic standpoint, similarly conducted expert surveys in other psychological domains (e.g., expert testimony on rape trauma and other abuse syndromes, the polygraph, parental competence in custody disputes, legal insanity) also have the potential to make important practical and forensic contributions.

\section{REFERENCES}

Berger, M. A. (2000). The Supreme Court's trilogy on the admissibility of expert testimony. In the Federal Judicial Center (Ed.), Reference manual on scientific evidence (2nd ed., pp. 9-38). Washington, DC: Federal Judicial Center

Ceci, S. J., \& Bruck, M. (1995). Jeopardy in the courtroom: A scientific analysis of children's testimony. Washington, DC: American Psychological Association.

Connors, E., Lundregan, T., Miller, N., \& McEwen, T. (1996). Convicted by juries, exonerated by science: Case studies in the use of DNA evidence to establish innocence after trial. Washington, DC: References U.S. Department of Justice.
Cutler, B. L., \& Penrod, S. D. (1995). Mistaken identification: The eyewitness, psychology, and the law. New York: Cambridge University Press.

Daubert v. Merrell Dow Pharmaceuticals, Inc., 113 S. Ct. 2786 (1993).

Devenport, J. L., Penrod, S. D., \& Cutler, B. L. (1997). Eyewitness identification evidence: Evaluating commonsense evaluations. Psychology, Public Policy, and Law, 3, 338-361.

Dunning, D., \& Stern, L. B. (1994). Distinguishing accurate from inaccurate eyewitness identifications via inquiries about decision processes. Journal of Personality and Social Psychology, 67, 818-835.

Faigman, D. L., Kaye, D. H., Saks, M. J., \& Sanders, J. (1997, Supp. 2000). Modern scientific evidence: The law and science of expert testimony. Eagan, $\mathrm{MN}$ : West.

Frye v. United States, 293 F. 1013 (D.C. Cir. 1923).

Kassin, S. M., \& Barndollar, K. A. (1992). On the psychology of eyewitness testimony: A comparison of experts and prospective jurors. Journal of Applied Social Psychology, 22, 1241-1249.

Kassin, S. M., Ellsworth, P. C., \& Smith, V. L. (1989). The "general acceptance" of psychological research on eyewitness testimony: A survey of the experts. American Psychologist, 44, 1089-1098.

Kassin, S. M., Ellsworth, P. C., \& Smith, V. L. (1994). Deja vu all over again: Elliott's critique of eyewitness experts. Law and Human Behavior, 18, 203-210.

Kassin, S. M., Rigby, S., \& Castillo, S. R. (1991). The accuracy-confidence correlation in eyewitness testimony: Limits and extensions of the retrospective self-awareness effect. Journal of Personality and Social Psychology, 61, 698-707.

Kirsch, I., \& Lynn, S. J. (1995). Altered state of hypnosis: Changes in theoretical landscape. American Psychologist, 50, 846-858.

Kumho Tire Co., Ltd. v. Carmichael et al., 526 U.S. 137 (1999).

Leippe, M. (1995). The case for expert testimony about eyewitness memory. Psychology, Public Policy, and Law, 1, 909-959.

Lindsay, D. S., Read, D. J., \& Sharma, K. (1999). Accuracy and confidence in person identification: The relationship is strong when witnessing conditions vary widely. Psychological Science, 9, 215-219.

Lindsay, R. C. L., Lea, J. A., Fulford, J. A. (1991). Sequential lineup presentation: Technique matters. Journal of Applied Psychology, 76, $741-745$.

Loftus, E. F. (1993). The reality of repressed memories. American Psychologist, 48, 518-537.

Luus, C. A. E., \& Wells, G. L. (1994). The malleability of eyewitness confidence: Co-witness and perseverance effects. Journal of Applied Psychology, 79, 714-723.

Malinoski, P. T., \& Lynn, S. J. (1999). The plasticity of early memory reports: Social pressure, hypnotizability, compliance, and interrogative suggestibility. International Journal of Clinical and Experimental Hypnosis, 47, 320-345.

McConkey, K. M., \& Sheehan, P. W. (1995). Hypnosis, memory, and behavior in criminal investigation. New York: Guilford Press.

Penrod, S. D., \& Cutler, B. (1995). Witness confidence and accuracy: Assessing their forensic relation. Psychology, Public Policy, and Law, I, 817-845.

Penrod, S. D., Fulero, S. M., \& Cutler, B. L. (1995). Expert psychological testimony on eyewitness reliability before and after Daubert: The state of the law and the science. Behavioral Sciences and the Law, 13, 29-259.

Pezdek, K., \& Banks, W. P. (Eds.). (1996). The recovered memory/false memory debate. San Diego, CA: Academic Press.

Pickel, K. L. (1999). The influence of context on the "weapon focus" effect. Law and Human Behavior, 23, 299-311.

Poole, D. A., \& Lamb, M. E. (1998). Investigative interviews of children: A guide for helping professionals. Washington, DC: American Psychological Association.

Read, J. D., \& Lindsay, S. D. (Eds.). (1997). Recollections of trauma: Scientific evidence and clinical practice. New York: Plenum.

Robinson, M. D., \& Johnson, J. T. (1999). How not to enhance the confidence-accuracy relation: The detrimental effects of attention to the identification process. Law and Human Behavior, 22, 409-428.

Ross, D. F., Read, J. D., \& Toglia, M. P. (Eds.). (1994). Adult eyewitness 
testimony: Current trends and developments. New York: Cambridge University Press.

Scheck, B., Neufeld, P., \& Dwyer, J. (2000). Actual innocence: Five days to execution and other dispatches from the wrongly convicted. New York: Doubleday.

Shaw, J. S., III. (1996). Increases in eyewitness confidence resulting from postevent questioning. Journal of Experimental Psychology: Applied, 2 , $126-146$.

Sporer, S. L. (1993). Eyewitness identification accuracy, confidence, and decision times in simultaneous and sequential lineups. Journal of Applied Psychology, 78, 22-33.

Sporer, S. L., Malpass, R. S., \& Koehnken, G. (Eds.). (1996). Psychological issues in eyewitness identification. Mahwah, NJ: Erlbaum.

Sporer, S. L., Penrod, S. D., Read, J. D., \& Cutler, B. L. (1995). Choosing, confidence, and accuracy: A meta-analysis of the confidence-accuracy relation in eyewitness identification studies. Psychological Bulletin, II $18,315-327$.

Steblay, N. M. (1992). A meta-analytic review of the weapon focus effect. Law and Human Behavior, 16, 413-424.

Stinson, V., Devenport, J. L., Cutler, B. L., \& Kravitz, D. A. (1996). How effective is the presence-of-counsel safeguard? Attorney perceptions of suggestiveness, fairness, and correctability of biased lineup procedures. Journal of Applied Psychology, 81, 64-75.

Stinson, V., Devenport, J. L., Cutler, B. L., \& Kravitz, D. A. (1997). How effective is the motion-to-suppress safeguard? Judges' perceptions of the suggestiveness and fairness of biased lineup procedures. Journal of Applied Psychology, 82, 211-220.

Technical Working Group for Eyewitness Evidence. (1999). Eyewitness evidence: A guide for law enforcement. Washington, DC: National Institute of Justice.

Thompson, C. P., Herrmann, D. J., Read, J. D., Bruce, D., Payne, D. G., \& Toglia, M. P. (1998). Eyewitness memory: Theoretical and applied perspectives. Mahwah, NJ: Erlbaum.

United States v. Amaral, 488 F. 2d 1148 (9th Cir. 1973).

Wells, G. L. (1993). What do we know about eyewitness identification? American Psychologist, 48, 553-571.

Wells, G. L., \& Bradfield, A. L. (1998). "Good, you identified the suspect": Feedback to eyewitnesses distorts their reports of the witnessing experience. Journal of Applied Psychology, 83, 360-376.

Wells, G. L., \& Bradfield, A. L. (1999). Distortions in eyewitness recollections: Can the postidentification feedback effect be moderated? Psychological Science, 10, 138-144.

Wells, G. L., Malpass, R. S., Lindsay, R. C. L., Fisher, R. P., Turtle, J. W., \& Fulero, S. M. (2000). From the lab to the police station: A successful application of eyewitness research. American Psychologist, 55, 581598.

Wells, G. L., Small, M., Penrod, S., Malpass, R. S., Fulero, S. M., \& Brimacombe, C. A. E. (1998). Eyewitness identification procedures: Recommendations for lineups and photospreads. Law and Human Behavior, 22, 603-648.

Yarmey, A. D., Yarmey, A. L., \& Yarmey, N. J. (1994). Face and voice identifications in showups and lineups. Applied Cognitive Psychology, $8,453-464$.

Yuille, J. C., \& Tollestrup, P. A. (1990). Some effects of alcohol on eyewitness memory. Journal of Applied Psychology, 75, 268-273. 